\title{
Appearing to Oneself (or not). Phenomenology and the Linguistic Turn
}

\author{
Pierre-Jean Renaudie \\ Université de Lyon \\ pjrenaudie@gmail.com
}

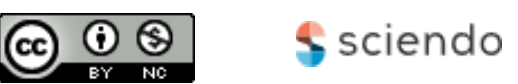

Reception date: $24-10-2017$

Acceptance date: 27-11-2017

\begin{abstract}
Do we appear to ourselves in a specific way that requires a phenomenological description? Do we need a phenomenology of self-knowledge? Another way to raise this question about the legitimacy of a phenomenological approach to the Self is to ask whether a philosophical analysis of the linguistic use of the personal pronouns is able to provide a satisfactory account of self-knowledge. Does the linguistic turn make phenomenology superfluous? Discussing the respective merits of the linguistic and phenomenological approaches to the concept of the Self through a crossed analysis of Sartre, Ricoeur, and Descombes, this paper stresses the complementarity between a phenomenological approach that focuses on the way we appear to ourselves and a linguistic analysis of the first-person pronoun. It claims that this relation of complementarity makes both approaches necessary to put forward the paradoxes of self-knowledge.
\end{abstract}

Keywords: Self, First-Person, Subjectivity, Descartes, Sartre, Descombes

Is there such a thing as a phenomenology of self-knowledge? Does a philosophical analysis of the concept of the self require a description of a specific kind of phenomenon, namely the experience of oneself? Does selfknowledge need to be grounded on the way one appears to herself? Vincent Descombes' last book Le parler de soi answers negatively to these questions, putting forward a 'philosophy of the first-person' that endorses the linguistic turn and is expected to overcome the shortcomings of the phenomenological claims regarding self-knowledge (Descombes, 2014). Quite surprisingly, 
Descombes' commitment to the linguistic turn and his discussion of the linguistic uses of the personal pronouns are based on the critique of the modern concept of subjectivity developed by Paul Ricoeur in Soi-même comme un autre $^{l}$. Drawing on Ricoeur's analyses, Descombes establishes a number of procedures designed to avoid the metaphysical pitfalls that undermine, according to him, the phenomenological approaches to the question of the self.

The rather unexpected fact that Descombes makes use of Ricoeur's account of the self against the phenomenological tradition might not be as surprising as it looks at first glance. It seems to be symptomatic of a self-critical tendency inherent to some recent developments of the phenomenological movement. The fascination for a linguistic analysis that points out the irrelevance of the phenomenological description and the pointlessness of an in-depth analysis of the ways things appear or manifest themselves is, arguably, the consequence of phenomenology's own inability to provide a fully satisfying account of language. The linguistic turn contributed in disqualifying the mode of investigation focused on the appearing of phenomena that the phenomenological tradition used to draw on, and left phenomenology struggling with the task to justify its own relation to language.

This paper aims to show that a phenomenological analysis of linguistic phenomena remains necessary and cannot be superseded by a strictly linguistic aproach - whether internal or external to the phenomenological tradition. Even if we acknowledge the necessity of a linguistic turn, the phenomenological focus on the way things appear remains necessary as a complementary account expected to fill the gaps of the linguistic analysis. In order to establish this point and to highlight the irreducibility of the phenomenological analysis, I will focus on the specific case of the use of the personal pronouns in self-knowledge, and propose a discussion of the conclusions that Descombes and Ricoeur draw from their analyses of the relations between the personal pronouns, leading them both to reject Sartre's account of the ambiguity of the first and third-person pronouns. I claim that Sartre's description of this ambiguity provides a phenomenological contribution to the study of linguistic phenomena that is more satisfying than a purely linguistic approach and that is not necessarily

${ }^{1}$ P. Ricœur, Soi-même comme un autre, Paris, Seuil, 1990 ; Eng. trans. Kathleen Blamey, Chicago, University of Chicago Press, 1992. 
committed to the misleading epistemic account of self-knowledge that both Descombes and Ricoeur criticize and reject.

\section{Who is the self that I happen to be? The problem of the 'philosophies of the subject'}

In order to make things clear, I will first try to characterize in very broad terms the specific approach to the question of the self defended by Vincent Descombes in Le parler de soi. The book is divided into three parts strongly connected to each other, dedicated respectively to a critical analysis of the classical notion of the Ego, a study of the systematic relations between the firstperson pronoun and the other personal pronouns, and an investigation of the paradoxes related to the expression of a belief. The two first parts are like the two opposite sides - positive and negative - of Descombes' philosophical analysis of the self.

The first part (negative) presents Descombes' reasons to criticize and reject what he calls the "philosophies of the subject". This first moment of the argument is both systematic and historical: it draws on an in-depth analysis of the invention of the Ego at the turn of the modern era in order to single out the deficiency of the metaphysical conception of the subject inherited from Descartes.

The second part attempts to develop a "philosophy of the first-person" grounded on the lessons that can be learnt from the mistakes of the philosophies of the subject in order to overcome its shortcomings. Descombes wants to acknowledge the existence of a new philosophical area, the philosophy of the first-person, which is expected to supersede the philosophies of the subject while providing a more satisfying understanding of the relations that tie together the personal pronouns and set the place of the first-person.

The third-part is to be understood as an appendix to these two first parts, which draws the conclusions from this philosophy of the first-person and applies them to the particular case of the belief. This last part is not only expected to reinforce the linguistic analysis defended by Descombes, but also to address a possible objection that emphasizes the subjective character of our beliefs. 
The strength of Descombes' argument lies in the complementarity of these three moments. The main objective of the book is to show that the disqualification of the Ego opens the space for a philosophy of the first-person that addresses the questions left unanswered by the traditional notion of the subject without endorsing its metaphysical commitments. This move requires (and is accomplished through) the linguistic turn: the reader is brought back from the ontological question about the nature of the Ego to a linguistic analysis of the conditions under which it is possible to make sense of the paradoxes and perplexities that constitute the metaphysical horizon of the classical understanding of the Ego or the Self ("le moi").

Descombes explains that the paradoxical character of the Self stems from the linguistic transformations that occurred in the $17^{\text {th }}$ Century, when the French words that used to function as first-person pronouns (moi, je) were nominalized and turned into a substantive: 'moi', a mere personal pronoun - not a proper noun - becomes 'le moi', a new word which plays the grammatical role of a substantive. This grammatical nominalization of a pronoun gives rise to a philosophical paradox that jeopardizes our understanding of the meaning of the word 'moi', insofar 'le moi' (unlike the pronoun 'moi') involves both the first and the third-person. The paradox consists in the possibility to understand the 'moi' at the same time as the object of which we speak in third person, and the subject or the speaker that utters this word. The word 'moi', in other words, encompasses two different things: the first-person pronoun (myself) and a noun that indicates a possible object of reference (the so-called 'Self'). This ambiguity creates a possible confusion between the first and third-person pronouns that is the source of the metaphysical difficulties intrinsically attached to the philosophies of the subject after Descartes according to Descombes. The problematic status of reflection for instance, is nothing but the expression of this difficulty (Descombes, 2014: 74): the reflecting subject is supposed to access to himself both as a subject and as an object.

This difficulty echoes an ambiguity in the original Latin version of Descartes' Metaphysical Meditations that makes it untranslatable in French or in English. It is impossible to tell in the Latin sentence whether Descartes uses 
the first or the third-person in his inquiry (Descombes, 2014: 59-60)2: does Descartes ask a question about himself ('I wonder who I am') or about his Ego ('I wonder who is this Ego that necessarily is each time that I think')? (Descombes, 2014: 71). This question is fundamentally unanswerable, since Descartes asks in fact two questions at once, a question about his identity and a question about his essence: a question about who he is and a question about what he is. While the first question can only be asked in first-person, the second needs to be formulated in third-person. This is why Descartes can jump from "it is certain that I am when I think" to the conclusion that he is "a thinking thing" (Descartes, 1996: 18).

The latin does not allow us to decide whether Descartes' investigation is directed towards himself or towards his self: 'moi' (myself) / 'ce moi' (my self, i.e. this self that happens to be mine). The 'Ego' that the philosophies of the subject deal with is the result of this confusing conflation between two different questions that the philosophical analysis should have kept separated.

In order to avoid the confusion that the nominalization of the Ego generates, Vincent Descombes proposes to follow a simple procedure that is meant to

\footnotetext{
${ }^{2}$ The difficulty arises from Descartes' ambiguous phrase, which involves both the first and the third person. This ambiguity urges the translator to make a choice that conceals the specificity of the original sentence and misses its philosophical subtelty. In the original French translation, the Duc de Luynes stresses exclusively the first-person : «Mais je ne connais pas encore assez clairement ce que je suis, moi qui suis certain que je suis» (R. Descartes, Méditations métaphysiques touchant la première philosophie, ed. Adam et Tannery, Paris, Vrin, 1982, p.19). Haldane and Ross' classical english translation follows the same path : «But I do not yet know clearly enough what I am, I who am certain that I am » (René Descartes, Meditations of First Philosophy, Eng. trans. E. S. Haldane and G. R. T. Ross, London, Routledge, 1993, 51). Conversely, the authoritative recent English translation of John Cottingham uses a grammatical construction that puts the emphasis on the third-person : "I must finally conclude that this proposition, I am, I exist, is necessarily true whenever it is put forward by me or conceived in my mind. But I do not yet have a sufficient understanding of what this «I » is, that now necessarily exists » (René Descartes, Meditations of First Philosophy, Eng. trans. J. Cottingham, Cambridge, Cambridge University Press, 1996, 17). Vincent Carraud stresses this difficulty and claims that the best French translation should be able to express the substantivation of the ego without departing from the first-personal conjugation of the verb « être » (to be), as follows: « Je ne comprends pas suffisamment qui je suis, moi, ce moi qui est désormais nécessairement » (V. Carraud, Pascal, des connaissances naturelles à l'étude de l'homme, Paris, Vrin, 2007, p. 122).
} 
protect us against the metaphysical issues related to the ambiguities of the concept of the Self (Descombes, 2014:78). Each time the word 'Moi' is nominalized and used as a substantive (' $l e$ moi'), we need to ask ourselves if this nominalization allows us to move back from the substantive to the pronoun, that is from a nominal or referential use to a pronominal use of the word. If this operation is possible, then we can go back from the noun to the pronoun that constitutes its grammatical origin, i.e. from 'ce moi' (this self) to 'moi' (myself). When this shift can be operated, the nominalization of the Ego is harmless, since we have the guarantee that the "self", which constitutes the object spoken about, designates nothing but the speaker, the individual or the empirical subject that makes use of the first-person pronoun. We are in this case still able to establish the "grammatical filiation" between the first-person pronoun and the noun (Descombes, $2014: 30-31)^{3}$.

This simple philosophical procedure allows Descombes to distinguish in the first part of the book two different conceptions of the self that allow us to understand the genesis of the misunderstandings generated by philosophers since the modern period ${ }^{4}$. On the one hand, some philosophers (as for instance the Port-Royal school and Pascal) address the question of the self from a moral perspective, binding it to the analysis of self-love. The self is understood as a particular attitude consisting in one's immoderate preoccupation about oneself: the self becomes the main object that such persons feel particularly inclined to talk about. In this case, the "grammatical filiation" from the pronoun to the noun is obvious, and we can always regress from the substantive ('le moi') to the pronoun ('moi'). The self of the moralist refers to the singular empirical individual who adopts this kind of attitude.

Yet, the self of the metaphysician has quite a different syntax, which disrupts the grammatical filiation from the pronoun to the noun. When Descartes speaks of his Ego, he does not refer to René Descartes, the empirical

\footnotetext{
${ }^{3}$ The idea of this grammatical filiation comes from an original synthesis between Ricœur and Wittgenstein. The expression is borrowed from Paul Ricœur (Ricœur 1990, 12), but echoes Wittgenstein's definition of the tasks for a grammatical philosophy, bringing the words back from their metaphysical use to their everyday use (Descombes 2014, 30). The philosophical aim of this analysis is faithful to Wittgenstein, but the method is borrowed from Ricœur.
}

${ }^{4}$ Ibid., 25-26, 78. 
individual who utters the words "I am, I exist", but to the subject of the general act of thinking. In this case, we lack of an individuation principle allowing us to identify the Ego in question. Who is this Ego? Not the person who speaks and uses the first-person pronoun. The philosophies of the subject are unable to account for the relation between the person who speaks of herself in first-person and the subject that the substantivation of the Ego is supposed to refer to. The linkage between the pronoun and the noun has been broken. Paradoxically, the philosophies of the subject fall short of their attempt to provide an account of the first-person and are doomed to speak of the Ego in third-person.

\section{The shift from the first to the third-person pronoun and the impossibility to pluralize "le moi"}

This analysis allows Descombes to translate into linguistic terms the difficulties raised by the question of the Ego and to propose a linguistic diagnosis of the problems inherently tied to the philosophies of the subject: although such philosophies emphasize the specificity of the first-person, they treat it as a subjective variety of the third-person ${ }^{5}$. According to Descombes, Sartre provides a paradigmatic example of this kind of grammatical mistake detrimental to his philosophical account of the self ${ }^{6}$. This error leads them to try to identify the subject designated by the first-person pronoun thanks to a referential procedure similar to the identification of a person designated by the third-person pronoun. The subject is expected to answer to the very same question that is usually formulated in third-person: the question "who am I?" is understood as raising the same kind of interrogation expressed in the question "who is he?". Consequently, the first question (about oneself) is usually translated into another question that has the grammatical form of the second (about someone), so that "who am I?" becomes "who is the ego?". The conclusion of this analysis, which meets Anscombe's criticism of the referential take on the first-person, is that the philosophy of the subject can only fail to explain the specificity of the first-person.

\footnotetext{
${ }^{5}$ Ibid., 134, 137-138.

${ }^{6}$ Ibid., 75.
} 
The second part of the book draws on this historico-grammatical analysis of the metaphysical shortcomings of the philosophies of the subject and sets the tasks for a proper "philosophy of the first-person". In order to provide a satisfying alternative to the philosophies of the subject, it needs to fulfil two complementary demands: a/ accounting for the relationship between the firstperson and the other personal pronouns and b/being able to highlight and maintain the logical specificity of the first-person pronoun (its irreducibility to the third-person). The philosophy of the first-person must show that the first person finds its meaning in its situation with respect to the system of the personal pronouns and let us understand how we can shift from one personal pronoun to the others. This possible shift from the first to the third-person is expected to account both for their difference and for the relation that ties them together.

This aspect of Descombes' philosophy of the first-person follows the method put forward by Paul Ricoeur in Oneself as another. According to Ricoeur, a philosophical analysis of the first-person needs to be able to account for the particular relation that ties together the first and the third-person pronouns, that is to understand "how the third person is designated in discourse as someone who designates himself as a first person" (Ricoeur, 1990: 48; 1992: 35). Ricoeur holds that "the possibility of shifting self-designation from the first to the third-person" defines the fundamental condition of a philosophical analysis of the first-person pronoun. Descombes uses this method as an antidote against the philosophies that ground their concept of subjectivity on the privileged access to oneself that one is supposed to enjoy (Descombes, 2014: 239).

The linguistic turn operated by the philosophy of the first-person that Ricoeur and Descombes champion transforms the unanswerable question raised by the philosophies of the subject into a question that we can make sense of. If being a subject amounts first and foremost to experiencing oneself in firstperson - if it is something that has to be experienced in first-person, then we cannot understand how this concept could be pluralized (Descombes, 2014: 237-238): I am by definition the only one to be myself if being myself requires a first-personal mode of accessing my own existence. The word 'moi' cannot be a true substantive since we cannot put it in plural: the French grammar does not allow us to speak of several mois, just as the English grammar forbids to 
pluralise the reflexive pronoun 'myself' (in myselves). The linguistic turn allows Descombes' philosophy of the first-person to shift the question from:

(A) "How many persons can be said to be 'myself'?"

to:

(B) “How many persons can say 'I', or 'myself'?"

Question (A) is unanswerable, while we can easily make sense of question (B). The latter is answerable as long as we are able to proceed to the shift described by Ricoeur in order to account for the first-person in a sentence formulated in third person. If this shift is possible, then we can make use of the third-person pronoun in order to describe something that was expressed in firstperson. In this case, to use Ricoeur's words, we understand "how the self can be at one and the same time a person of whom we speak and a subject who designates herself in the first person"7. When someone tells us that she is in pain, for instance, it does not matter whether or not we can feel her pain or access it one way or the other; the only thing that matters is that we be able to translate the sentence that expresses her pain in first-person into a sentence formulated in third-person that everyone is able to understand: 'she is in pain'. The possibility of this linguistic shift is enough to provide an account of the first-person that does not require or presuppose a theory of reflection: understanding what being a subject is about is not a matter of one's access to her own experiences, it is first and foremost a matter of being able to translate into the third-person a sentence formulated in first-person.

\section{A phenomenology of the linguistic use of the personal pronouns}

I now come to the questions I wanted to raise with respect to the conclusions that Vincent Descombes draws from these analyses. The linguistic procedure that Descombes borrows from Ricoeur requires that we disregard any kind of

${ }^{7}$ Ricœur (1990), 48 ; (1992), 35. 
ambiguity attached to the uses of the personal pronouns. Our ability to shift from the first to the third person according to this procedure presupposes the grammatical impermeability of the personal pronouns: it is clear to Descombes that the use of the third-person pronoun must allow us to translate sentences formulated in first-person without ambiguity. The great virtue of this theory is to discard as irrelevant the epistemic issues related to the 'phenomenological' claims regarding the way one appears to herself ${ }^{8}$. If someone says that she feels ashamed, we do not need to wonder how it is possible to know with absolute certainty that it is so ${ }^{9}$; the only question that a philosophy of the first-person needs to answer is whether we understand the meaning of the sentence "she feels ashamed", and the answer to this question is obviously positive.

Consequently, Descombes rejects firmly Jean-Paul Sartre's analysis of the literary ambiguity of the third-person. Descombes and Ricoeur's endorsement of the linguistic turn commits them to a theory that leaves no space whatsoever for any ambiguity likely to affect our use of the personal pronouns. Refusing to share Sartre's concerns regarding the ways personal pronouns are used in literature, they both reject the rigid literary rules that Sartre sets up in order to avoid the ambiguities intrinsically attached, according to him, to our uses of the personal pronouns. In the last part of this paper, I will show that Sartre's position, though impossible to defend with respect to the theory of the novel, relies on an aspect of the analysis of the relations between personal pronouns that Descombes and Ricoeur are bound to miss, and that is necessary to the analysis of linguistic phenomena.

The literary realism defended by Sartre commits him to a theory according to which the writer of novels has to choose between two options in order to describe the actions of his characters: either he needs to use the first-person pronoun in order to narrate the story through the eyes (or from the perspective) of the agent; or he has to adopt an external viewpoint on the actions of the protagonists and describe them "from outside" with the help of the third-person pronoun, as if they were seen by someone else. "The novelist must be either inside or out. Because M. Mauriac does not observe these laws, he does away

\footnotetext{
${ }^{8}$ Descombes (2014), 29

${ }^{9}$ Ibid., 246
} 
with his characters' minds." 10 The writer needs to keep away from an ambiguous use of the pronouns that would threaten the credibility of his narration. Sartre provides several examples of this mistake in Mauriac's descriptions of the feelings and states of mind of his main character, Thérèse. Sartre would allow Mauriac to write a sentence like: "she was trembling", but he finds a fundamental literary flaw in sentences such as: "She could not help but be aware of her lie; she settled down into it, made her peace with it."11

Sartre provides an epistemic reason for this literary principle: "This behaviour is something I have no way of knowing except through Therese herself." 12 There is no way of knowing what exactly Thérèse's awareness of her lie is about, unless I am in her position, that is to say in a position allowing me to say in first-person "I made peace with my lie". The ambiguous use of the third-person pronoun that Sartre ascribes to Mauriac's writing style results from some epistemic considerations regarding the cognitive information available to the speakers: the use of the first-person pronoun should be grounded on a kind of access to oneself that cannot be available to the user of the third-person pronoun. With this respect, Sartre's theory falls undeniably under Descombes' criticisms.

However, I think that we can give a 'grammatical' interpretation of this theory that might be philosophically more subtle and that would give a different significance to the ambiguity of the pronouns. Even if we agree with Descombes that Sartre's account of the literary ambiguity of the third-person relies on a problematic account of the epistemic conditions attached to the linguistic uses of the personal pronouns, we might nevertheless acknowledge that Sartre's analysis stresses an interesting difficulty. In other words, even if Sartre provides a wrong answer to the question he raises, he might still be asking the right question. So I will purposefully leave aside the epistemic considerations that constitute the background of Sartre's analysis in order to try to provide a different (and more generous) reading of his analysis of the ambiguity of the third-person.

${ }^{10}$ J.-P. Sartre, Situations 1, Paris, Gallimard, 1947, p. 44 ; Eng. Trans. A. Michelson, Literary and Philosophical Essays, New York, Collier Books, 1962, p. 17

${ }^{11}$ Sartre (1962), 13

${ }^{12}$ Ibid. 
When Sartre focuses on the possibility of an ambiguous use of the thirdperson pronoun, he in fact attempts to answer a question that seems very close to the problem addressed by Descombes' book. Sartre's concerns regarding Mauriac's litterary style stem from the difficulties raised by the very point that both Descombes and Ricoeur put forward: if it is possible to shift so easily from the first to the third-person pronoun, this operation might have a certain cost, which Sartre tries to evaluate. His analysis of the literary ambiguity of the thirdperson must be understood within the frame of a wider philosophical project that arose started to be developed in Transcendence of the Ego ${ }^{13}$ : understanding the risks intrinsically related to the fact that we are able to describe a mental state that should be expressed in first-person with the help of the third-person pronoun. This very question constitutes the heart of Vincent Descombes' inquiry, which aims to assess the legitimacy and the cost of third-personal accounts of the self.

This is exactly what Sartre is targeting in his criticism of the first-personal use of the third-person pronoun on which Mauriac's literary style draws constantly. The main risk of such ambiguous uses of the personal pronouns is to dismiss the incorrigibility that characterizes specifically the use in firstperson and in present tense of what Wittgenstein used to call the 'psychological verbs', and so to conflate two essentially different ways of speaking of one's mental states. When Thérèse speaks in first-person of the way she feels, she expresses her states of mind in a way that does not leave any room for contestation and does not need any justification. Descombes stresses this aspect of Wittgenstein's analysis: it would not even make sense to ask her how she knows that she feels what she says that she feels or has such or such intention ${ }^{14}$.

Sartre holds that the situation is very different when Mauriac describes Thérèse's experience of her feelings. The question remains open whether or not the narrator's description of the characters' inner states should be granted a similar kind of incorrigibility and whether his description can function as an expression (in the technical sense) of the characters' states of mind. We must at least admit that this point can be discussed, insofar as the use of the third-

\footnotetext{
${ }^{13}$ J.-P. Sartre, La transcendance de l'ego, Paris, Vrin, 1936 ; Eng. trans. Williams and Kirkpatrick, New York, Hill and Wang, 1960

${ }^{14}$ Descombes (2014), 126
} 
person pronoun opens a logical gap between the description and the state of mind described that is not presupposed by the expressive use of the first-person: when the narrator describes Thérèse's feelings in third-person, there is at least room for a certain scepticism and for a demand of justification; such a demand is not as nonsensical as it would be in the case of an expression in first-person. One might argue that some literary conventions can grant some kind of a priori infallibility to the narrator as long as he does not take part in the story. But the important point here is that it is not always the case, as Stanley Cavell pointed out in his study of Edgar's monologue in Shakespeare's King Lear ${ }^{15}$. If there is such a convention, it is an exceptional one, which applies exclusively to the narrator's use of the third-person in a novel, but does not affect the everyday use of the third-person pronoun.

\section{The existential ambiguities of our use of the personal pronouns}

So to sum up the point I am trying to make, I propose to consider the two following sentences that express the same thing in first and third-person:

(A) I made my peace with the lie that I cannot help but be aware of

(B) She made her peace with the lie that she could not help but be aware of

The fact that we can always shift from an expressive use of the first-person (A) to a third-person description of the states of mind expressed (B) does not imply that one is legitimated to make an expressive use of the third-person pronoun. The ambiguity in Mauriac's style stems from his attempt to make an expressive rather than descriptive use of the third-person, which results in blurring the distinction between these two very different ways of accounting for one's states of mind. This is why it is not very clear whether or not we can ask for some justification when Mauriac describes Thérèse's feelings. It is not

\footnotetext{
${ }^{15}$ S. Cavell, Must we mean what we say? A book of Essays, Cambridge Univesity Press, 2002 (1976), 336. Even more so than Shakespeare's play, Agatha Christie's novel The murder of Roger Ackroyd deals with the problematic reliability of the narrator's account of the story.
} 
completely meaningless to do so; otherwise we wouldn't even be able to make sense of the question that Sartre asks. We can understand (B), but not without adding to the description a minimal form of scepticism that was absent from the expression of (A).

Interestingly, Sartre's analysis of the possibility of a first-personal use of the third-person pronoun echoes another aspect of his philosophy that might look at first completely distinct and foreign, but draws on the same philosophical point. Sartre's descriptions of the reification of oneself that results from a deceitful form of reflection and leads to what he calls bad faith are in fact strictly parallel to this criticism of Mauriac's literary style: while the latter focuses on a "first-personal use" of the third-person pronoun, the former analyses a kind of "third-personal use" of the first-person pronoun. These two analyses have the same function: they both put forward the tendency to conflate the expressive and descriptive speeches whenever what is spoken about is one's states of mind. The use of the first and third-person pronouns is ambiguous not because of their linguistic determinations - they are not ambiguous in themselves, but because of the way we use them. In other words, the ambiguity is not semantic but pragmatic: it is not related to the meaning of the pronouns but is contingent on what we do with them when we use them.

Consequently, Sartre's emphasis on the ambiguity attached to our way of making use of the personal pronouns does not dismiss the point put forward by Ricoeur and Descombes. On the contrary, it draws on an analysis of the relation that ties the personal pronouns together and allows us to shift so easily from the first to the third-person. The ambiguity arises from the fact that it is possible to use the third-person pronoun to express one's states of mind, as well as to make use of the first-person pronoun in order to describe one's state of mind on a mode exactly similar to the way I would describe another's. The question is not whether one should be entitled to use personal pronouns in such ways, the point is only that this way of using the first-person pronoun cannot be a priori ruled out. Making use of the first-person pronoun in order to describe in present tense one's own states of mind might be delusive and misleading - as Descombes claims, but it is not completely meaningless: otherwise we would not even be able to explain why so many philosophers fell into the "descriptivist illusion" (Descombes, 2014: 364) and took expressive statements for a form of selfascription of mental states. Such statements are intrinsically open to this kind 
of mistake, because of the different possible uses of the personal pronouns that make them ambiguous linguistic devices. By paying attention to the diversity and intrinsic ambiguity of the linguistic uses of the personal pronouns, Sartre provides the grounds for a phenomenological approach to linguistic phenomena that goes beyond a strictly linguistic analysis of the grammatical function of the personal pronouns and focuses on the linguistic experience thanks to which one achieves self-reference.

\section{Bibliography}

Carraud, V. (2007). Pascal, des connaissances naturelles à l'étude de l'homme. Paris: Vrin.

CAVELl, S. (2002 [1976]). Must we mean what we say? A book of Essays. Cambridge: Cambridge Univesity Press.

DesCARTES, R. (1982). Méditations métaphysiques touchant la première philosophie. Adam et Tannery (eds.). Paris: Vrin. Eng. trans.: E. S. Haldane and G. R. T. Ross, London, Routledge, 1993; Eng. trans.: John Cottingham. Cambridge : Cambridge University Press, 1996

DESCOMBES, V. (2014). Le parler de soi. Paris: Gallimard.

SARTRE, J.-P. (1936). La transcendance de l'ego. Paris: Vrin, 1936. Eng. trans.: Williams and Kirkpatrick. New York: Hill and Wang, 1960.

- (1947). Situations 1. Paris: Gallimard. Eng. trans.: A. Michelson. Literary and Philosophical Essays. New York: Collier Books, 1962

Ricoeur, P. (1990). Soi-même comme un autre. Paris: Seuil. Eng. trans.: Kathleen Blamey. Chicago: University of Chicago Press, 1992.

PIERRE-JEAn RENAUdiE is PhD from the Paris-Sorbonne University. Teaches philosophy at the University of Lyon (Lyon III - Jean Moulin). He is the author of a book on Husserl's theory of knowledge (Husserl et les categories. Langage, pensée et perception, Paris, Vrin, 2015) and published many articles, in French and in English, on the phenomenological tradition. 